\title{
Experimental Study on the Creep Behaviour of Cemented Sand and Gravel (CSG) and Temperature Stress Prediction of CSG Dam under Seasonal Temperature Change
}

\author{
Xin Cai $\mathbb{D}^{1,2}$ Minmin Jiang $\mathbb{D}^{1},{ }^{1}$ Xingwen Guo $\mathbb{D}^{,},{ }^{2}$ Jiaojiao Chen, ${ }^{1}$ and Qian Zhao ${ }^{3}$ \\ ${ }^{1}$ College of Water Conservancy and Hydropower Engineering, Hohai University, Nanjing 210098, China \\ ${ }^{2}$ College of Mechanics and Materials, Hohai University, Nanjing 210098, China \\ ${ }^{3}$ State Grid Anhui Electric Power Research Institute, Hefei 230601, China
}

Correspondence should be addressed to Minmin Jiang; jmm@hhu.edu.cn

Received 9 October 2019; Revised 31 December 2019; Accepted 16 January 2020; Published 19 February 2020

Academic Editor: Lukasz Sadowski

Copyright (C) 2020 Xin Cai et al. This is an open access article distributed under the Creative Commons Attribution License, which permits unrestricted use, distribution, and reproduction in any medium, provided the original work is properly cited.

Creep generally showed a great impact on the temperature stress of concrete structure. At present, little research has been done on the creep law of cemented sand and gravel (CSG), and the calculation of creep temperature stress mainly adopts a set of relevant parameters. In this context, experimental compressive creep tests were carried out on the specimens of large-sized cylinders with different cementing agent contents; the creep temperature stress of CSG was also calculated. The results showed that the creep of CSG increased with the increase of cementing agent content, but the specific creep was not obvious. In addition, the creep model of CSG with high accuracy was also obtained, which could provide a basis for the numerical simulation of CSG dam. Furthermore, the results of numerical simulation showed that creep has a great influence on the stress of CSG dam, and the thermal stress energy was less than $37 \%$. At the same time, it was necessary to determine whether temperature control should be considered according to different cementing agent content and external climate conditions, which cannot be generalized.

\section{Introduction}

Cemented sand and gravel (CSG) dam is a new type of dam developed on the basis of faced rockfill dam and roller compacted concrete (RCC) dam [1]. CSG mainly consists of sand and gravel, which was typically obtained from the construction site without screening and washing; besides, a small amount of cementitious materials (cement, fly ash, etc.) and water is mixed in CSG [2]. After simple mixing, subsequent spreading, and rolling, the materials with certain strength and shear resistance are formed. The cementing agent content of this dam is between rockfill material and RCC, generally in the range of $0-140 \mathrm{~kg} / \mathrm{m}^{3}$ [3]. CSG dam showed the advantages of convenience and fast construction, being economical, eco-friendly availability, simple temperature control, and good seismic performance [4]. Therefore, CSG dams were widely used in various infrastructures, including embankments, reinforcements of small rural hydropower structures, and dam construction. Currently, more than 50 CSG dams or cofferdams have been constructed worldwide [5].

For CSG, more and more attention has been paid to the study of material properties and structural characteristics. Jia et al. [6], Lohani et al. [7], and others have carried out a series of strength tests of CSG. Kongsukprasert and Tatsuoka [8], Cai et al. [9], and Yang et al. [10] developed several constitutive models of different types of CSG based on the results of large triaxial tests. These relevant researches provide the reference basis for the following projects and deepen the understanding of the characteristics of CSG dams, but the studies on temperature control of CSG dam are still rare. With the development of CSG dam construction to medium and high dams, the high casting speed results in the considerable temperature stress, while the permissible tensile strength of CSG dam is low and still faces the risk of cracking. Therefore, in-depth research 
on the temperature control and crack prevention of CSG dam is necessary.

In the calculation of temperature stress, the temperature stress with creep considered can be reduced by $34-44 \%$ compared with that without creep [11]. Therefore, the study of creep characteristics of CSG was an important part of its temperature control research. At present, a lot of researches on creep characteristics of concrete and other materials have been carried out. Bazant et al. [12, 13] introduced a new model of concrete creep and shrinkage characteristics in concrete structure design. Compared with the previous models, this model is more concise and has good agreement with the experimental data. For different temperature stress testing machines (TSTM), the testing process of cracking age, the stiffness development, and stress relaxation caused by creep are quite different. Staquet et al. [14] and Delsaute et al. $[15,16]$ summarized the development and shortcomings of TSTM and developed a new test system and test procedures to study the sensitivity to cracking of concretes. $\mathrm{Wu}$ and Luna [17] proposed a three-dimensional finite element program to calculate the temperature stress considering multiple factors, which simulated the construction process of mass. Abdulrazeg et al. [18] studied the effects of temperature on the elastic and creep properties of roller compacted concrete. The results show that in the initial stage the growth of elastic modulus is accelerated, and the stress is increased because of the high hydration temperature. The maximum principal stress increased by $40 \%$ in the initial stage. Under the same test conditions, He et al. [19] conducted compression creep and shrinkage tests on rock-filled concrete (RFC) and self-compacting concrete (SCC) specimens with different loading ages. The results show that loading time has little effect on creep strain. Both creep strain and shrinkage strain of RFC are smaller than SCC. Delsaute and Staquet [20] studied the effect of the substitution of natural coarse gravel and sand by recycled gravel and sand on the early age development of the volume change and the mechanical properties. It is concluded that the basic creep phenomenon increases obviously in the early stage when using recycled aggregate. The results can provide reference for the subsequent research of recycled gravel and sand. In the field of CSG, Guo et al. [21, 22] established a reasonable creep model of CSG from macro and micro angles through experiments and verified the accuracy of this model. Feng [23] experimentally studied the creep properties of CSG with a cementing agent content of $80 \mathrm{~kg} / \mathrm{m}^{3}$, and the creep properties of the CSG were preliminarily discussed. Wu et al. [24] simulated the creep temperature stress of CSG dam using the creep formula of a project, and the simplified temperature control measure was put forward.

Although some studies have been carried out on the creep temperature stress of CSG, the relevant parameters were made just based on the RCC dams or classical formulas. This leads to some deviations in the simulation results; however, there is still no creep model of CSG with time proposed until now. In view of the above problems, creep tests of CSG with different cementing agent contents and 28 days of loading age were carried out in this study. The creep and specific creep characteristics of CSG were analyzed, and a creep model suitable for CSG was also constructed. Through the finite element simulation, the variation law of creep temperature stress for CSG dam was analyzed, and whether temperature control measures should be taken into account in this dam type was discussed.

\section{Experimental Program}

2.1. Test Materials and Grouping. Referring to the SL6782014 technical guidelines [25] for cemented granular material dams, the cementing agent for CSG was the P. C.42.5 ordinary Portland cement with grade I fly ash mixing in a ratio of $1: 1$. Medium coarse sand obtained from the Nanjing market was used as the fine aggregate. Cobblestones found in the suburbs of Nanjing were used as the coarse aggregates. The sample density was $2360 \mathrm{~kg} / \mathrm{m}^{3}$, and the water-binder ratio was 1.0. The cumulative particle gradation percentage diagram is shown in Figure 1.

Creep tests of CSG included four groups of uniaxial creep tests with the cementing agent content of $40,60,80$, and $100 \mathrm{~kg} / \mathrm{m}^{3}$. Four specimens were used in each test, two of which were used as the contrast specimens, and the specific ratio is shown in Table 1.

In uniaxial compression creep test, strain sensors with appropriate range and sensitivity were needed. The determination of range and sensitivity was generally related to the material strength and elastic modulus. At present, Zhao [26] carried out the tests on strength and elastic modulus of CSG. The focus of this study was to carry out creep test research, so the strength and elastic model test will no longer be carried out. In this study, appropriate strain sensors were selected by referring to the relevant data obtained by Zhao [26].

2.2. Instrumentation. The test instruments mainly included spring compression creep tester with the maximum axial compression load less than $200 \mathrm{kN}$, DI-25 Differential Resistance Strain Meter with a distance of $250 \mathrm{~mm}$ and a range of $-1000-600 \mu \varepsilon$ (negative indicates the compression), QS-5 digital bridge, $50 \mathrm{t}$ hydraulic jack, force sensor with the maximum range of $50 \mathrm{kN}$, and steel die with the specification of $\Phi 200 \mathrm{~mm} * 600 \mathrm{~mm}$.

\subsection{Test Procedure}

2.3.1. Mixing of CSG. Considering the discrete mechanical properties of CSG, the influence of external factors on the composition of the specimen was minimized in this study. All the test specimens of each group were poured to complete the one-time mixing of CSG. Due to the large amount of stirring, a medium-sized mixer with a maximum stirring volume of $0.4 \mathrm{~m}^{3}$ was adopted to eliminate the human interference. Firstly, the coarse aggregate and sand were weighed according to the mix proportion and aggregate gradation and then evenly stirred, after which the weighed cement and fly ash were poured and evenly mixed with the premixed gravel. Finally, the appropriate amount of water was added in batches and mixed with the above material. The mixing process can be seen in Figure 2. 


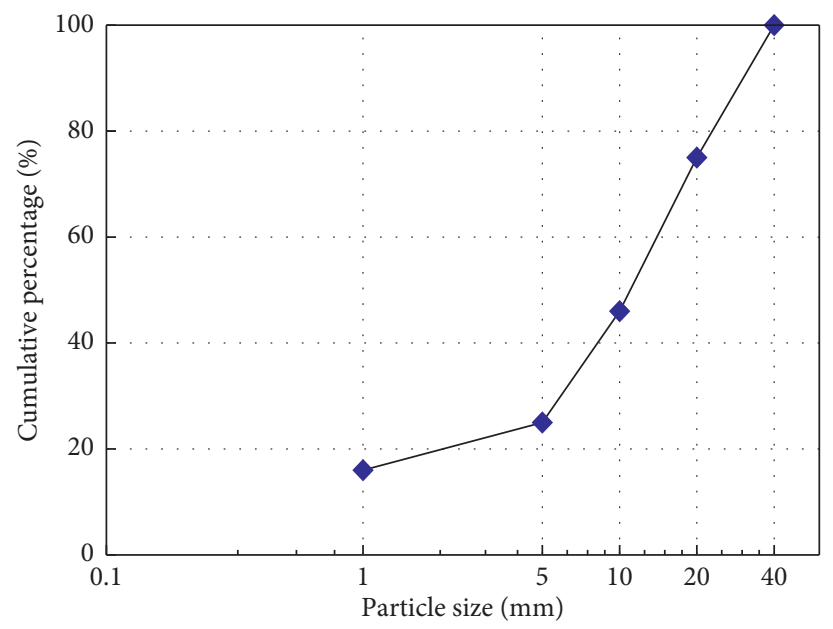

FIgURE 1: Cumulative particle gradation percentage of CSG.

TABLE 1: Proportion of cementitious material.

\begin{tabular}{lccccc}
\hline Sequence number & Cement $\left(\mathrm{kg} / \mathrm{m}^{3}\right)$ & Fly ash $\left(\mathrm{kg} / \mathrm{m}^{3}\right)$ & Water $\left(\mathrm{kg} / \mathrm{m}^{3}\right)$ & Fine aggregate $\left(\mathrm{kg} / \mathrm{m}^{3}\right)$ & Coarse aggregate $\left(\mathrm{kg} / \mathrm{m}^{3}\right)$ \\
\hline 1 & 50 & 50 & 100 & 540 & 1620 \\
2 & 40 & 40 & 80 & 550 & 1650 \\
3 & 30 & 30 & 60 & 560 & 1680 \\
4 & 20 & 20 & 40 & 570 & 1710 \\
\hline
\end{tabular}

2.3.2. Specimen Preparation. The creep specimen was a cylinder with a diameter of $200 \mathrm{~mm}$ and a height of $600 \mathrm{~mm}$. Considering the low strength and the uneven surface of the CSG, $40 \mathrm{~mm}$ high strength cement mortar was poured into the upper and lower parts of the cylinder to protect the specimens and for test requirements. The composition of the specimens was shown in Figure 3. The pouring of CSG used vibrating rod for vibration and compaction; the CSG was divided into four layers and the thickness of each layer was $13 \mathrm{~cm}$. During the creep test, the embedded specimens should be kept in the center of the specimens and be perpendicular to the top and bottom of the specimens. To meet this requirement, RCC creep specimens were selected to insert a rod at the location of the embedded strain gauge and then be compacted; the rod was slightly larger than the strain gauge. Finally, the rod was pulled out and the strain gauge was buried. The burial selection of strain gauge should be consistent with the RCC concrete due to the low cementing agent content of CSG. The strain meter consists of three main parts: the sensor, the sealing shell, and the lead cable, as shown in Figure 4.

The digital bridge is a kind of receiver specially designed for measuring and reading unbonded elastic wire resistance type strain meter, as shown in Figure 5. Firstly, a calibrated and qualified strain gauge was used in the test, and a bridge was used to measure the resistance value $R$ and the resistance ratio variation $Z$ in real time. Finally, the deformation of the specimen was calculated according to the recommended formula in the test code for hydraulic concrete [27]. The pouring process was shown in Figure 6. After 2-3 days of pouring, the die could be removed and the specimen side showed a honeycomb structure, as shown in Figure 7.
2.3.3. Surface Treatment and Maintenance of Specimens. Generally, the creep of CSG was affected not only by load but also by ambient temperature and humidity. In order to study the effect of load on the creep of CSG, other influencing factors should be excluded. The specific operation methods were shown as follows. Firstly, the surface of specimen was coated with the asphalt paint, as shown in Figure 8 . Then the melted paraffin and rosin (ratio at $3: 1$ ) mixture with a certain thickness was coated after the surface asphalt paint was dried, as shown in Figure 9. After the surface treatment, the specimens were maintained at constant temperature of $20^{\circ} \mathrm{C}$ for 28 days.

2.3.4. Creep Specimen Loading. According to the specification [27], the specimen is first installed on the compression creep meter. Then a disk containing steel balls was placed at both ends of the specimen to ensure that the specimen was in the state of axial compression. The position and fixing mode of the specimen on the creep tester are shown in Figure 10.

Next, the preloading was to obtain the elastic modulus of the cylindrical specimen. Generally, the method of preloading in creep test is to apply the pressure slowly by jack, and the maximum preloading stress is 0.3 times of the failure strength of the specimen. Load was measured in real time by force sensor and dynamic acquisition instrument. Repeated preloading of 3 times was carried out until the difference between the two adjacent deformation values was not more than $0.003 \mathrm{~mm}$. Otherwise, the preloading should be continued until the difference meets the requirements. Finally, the jack was used to exert the pressure slowly until the load 


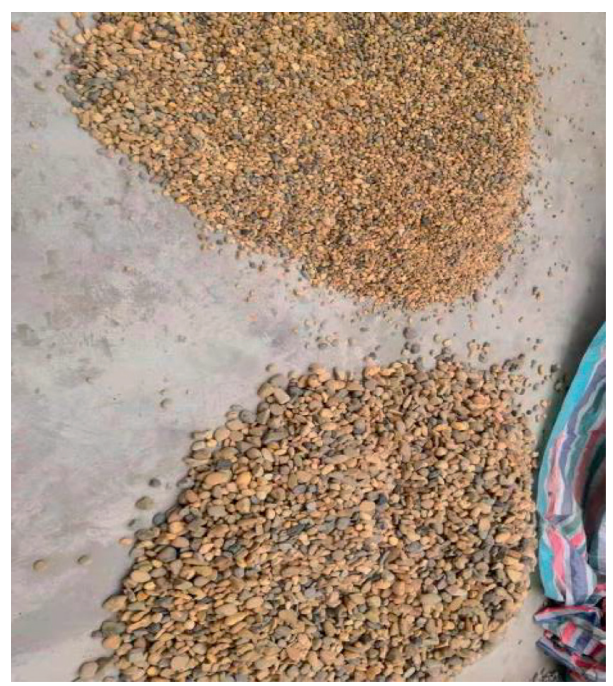

(a)

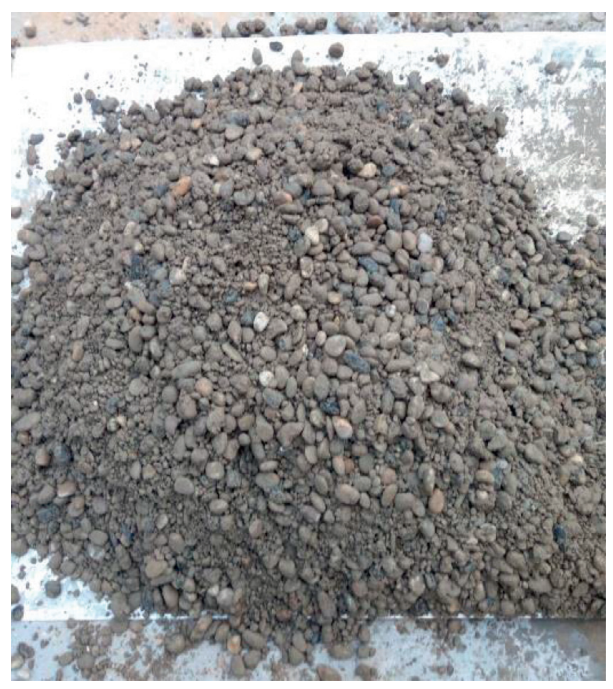

(c)

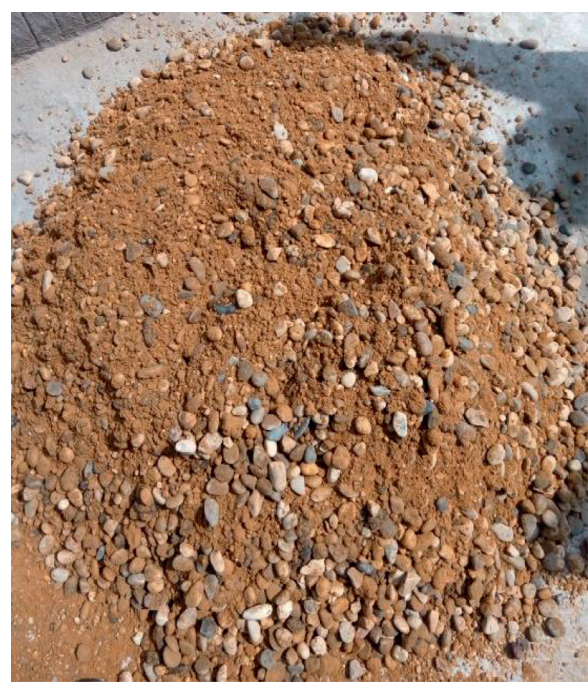

(b)

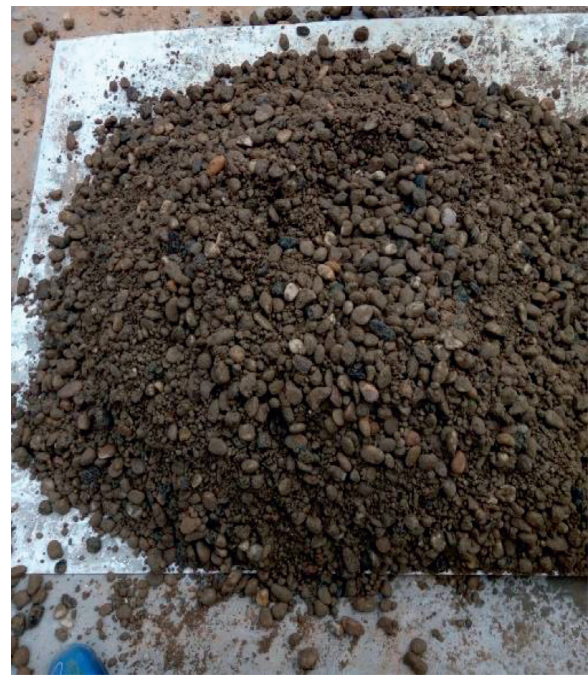

(d)

FIgURE 2: The mixing process of CSG. (a) Sieve the coarse aggregate. (b) Coarse and fine aggregate mixing. (c) Mix the cement and fly ash. (d) Add water and mix in three batches.

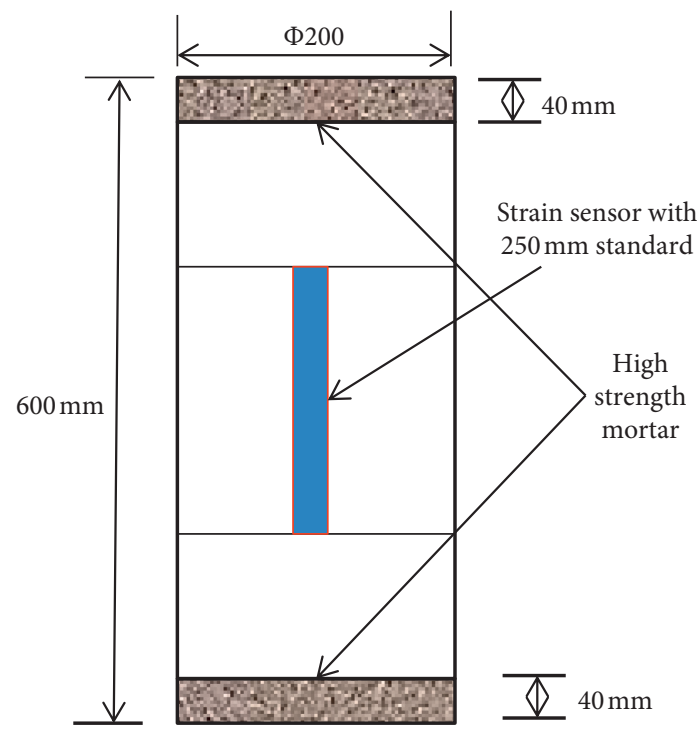

Figure 3: Composition of specimens.

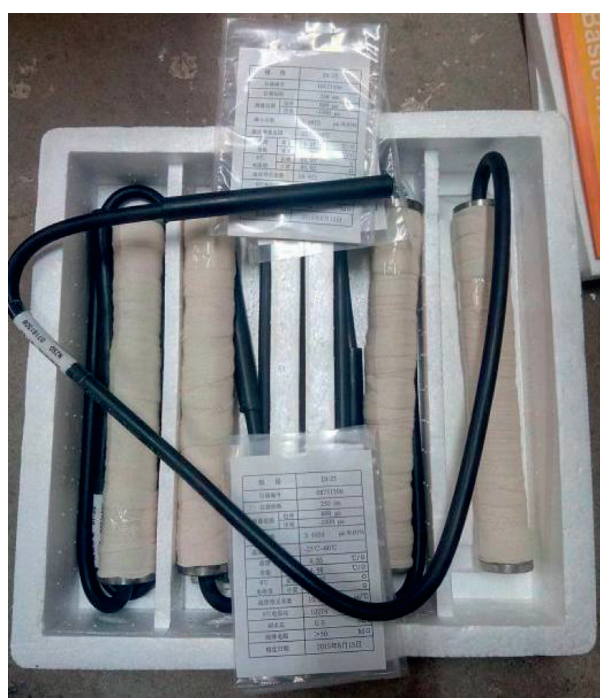

FIGURE 4: DI-25 unbonded elastic wire resistance type strain meter. 


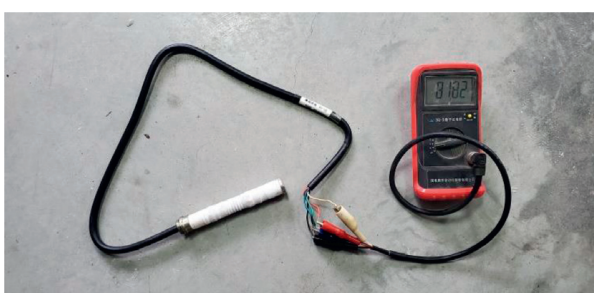

FIGURE 5: SQ-5 digital bridge.

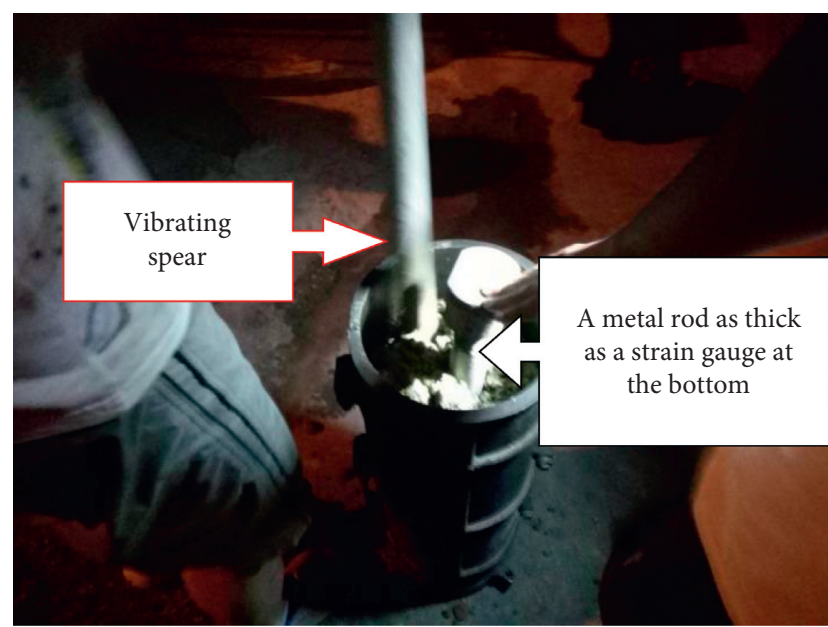

Figure 6: Pouring site.

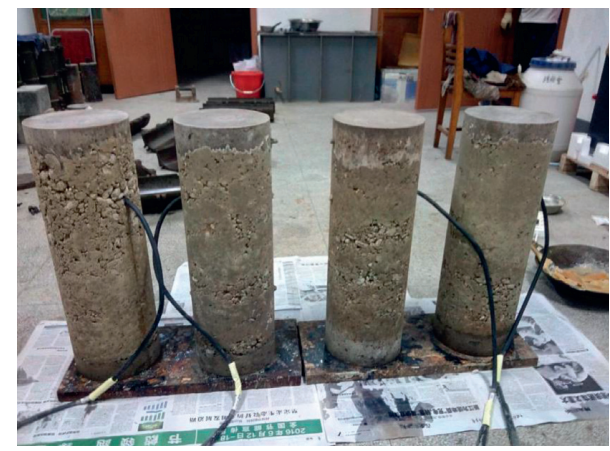

Figure 7: Appearance of specimen.

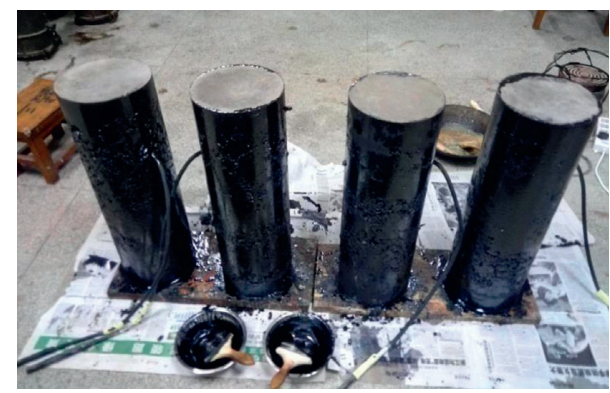

Figure 8: Asphalt paint on the surface of the specimen.

reached 0.3 times of the failure strength of the specimen. The elastic modulus of the creep specimen and the compressive strength of the cube specimen measured by the test are

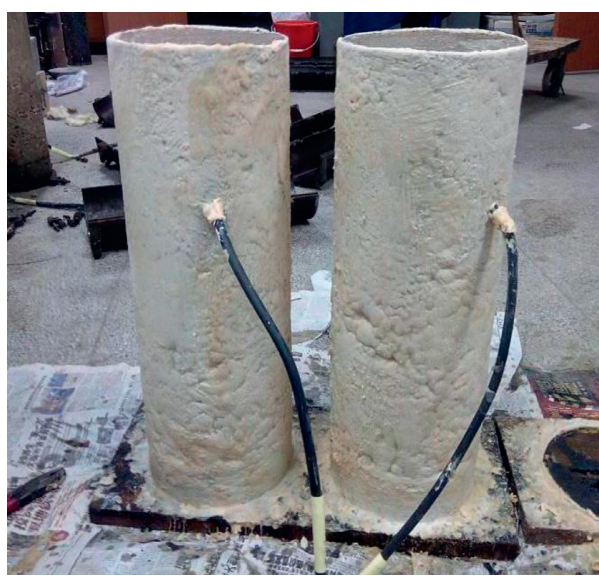

Figure 9: Brush the mixture of paraffin and rosin.

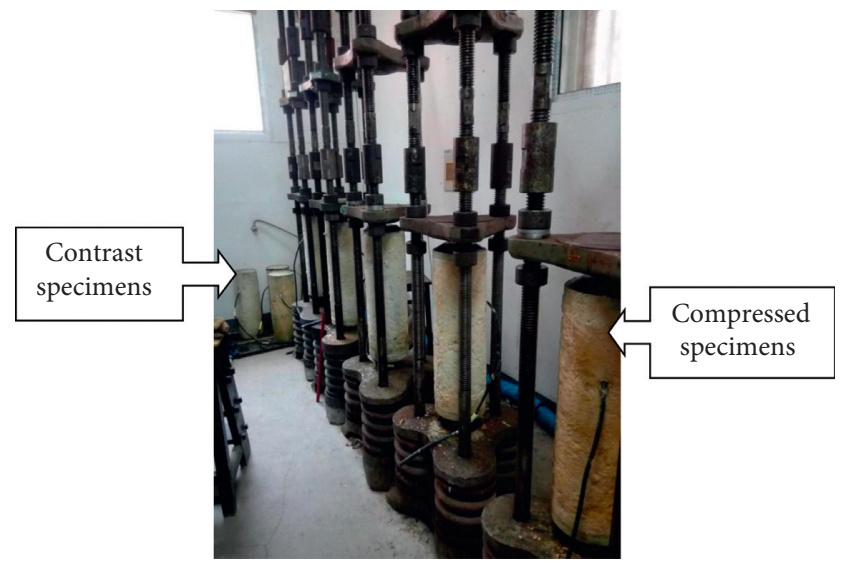

FIgURE 10: Schematic diagram of specimen mounting.

shown in Table 2, compared with the data from [28]; the results of this experiment are relatively lower. The main reason is that sun [28] used river sand, while yellow sand with high mud content was used in this experiment.

\section{Results and Discussion}

3.1. Analysis of Test Results. Figures 11 and 12 show the variations of creep and specific creep over time for the CSG samples with different cementing agent contents. Specific creep refers to the creep under the action of unit stress, that is, the creep value divided by the load of the specimen, which can be expressed as

$$
C(t, \tau)=\frac{\varepsilon_{\mathrm{cr}}(t, \tau)}{\sigma},
$$

where $C(t, \tau)$ refers to the creep function in units of $10^{-6} /$ $\mathrm{MPa} ; \varepsilon_{\mathrm{cr}}$ is the basic creep strain of the loaded specimen and $\sigma$ is the uniaxial stress applied on the loaded specimen. As shown in Figure 8, a certain amount of the short-term creep with similar properties as in the literature [20,29] was observed after loading, and then the creep deformation occurred. In the early stage of loading, the creep develops rapidly; then the creep rate gradually decreases and finally enters into a stable creep stage, in which the creep rate 
TABLE 2: Elastic modulus and compressive strength of the test specimens.

\begin{tabular}{lcc}
\hline Cementing agent content $\left(\mathrm{kg} / \mathrm{m}^{3}\right)$ & Elastic modulus $(\mathrm{GPa})$ & Compressive strength $(\mathrm{MPa})$ \\
\hline 40 & 7.72 & 0.54 \\
60 & 9.05 & 1.07 \\
80 & $9.24 / 11.21^{*}$ & $1.27 / 2.94^{*}$ \\
100 & $11.58 / 13.84^{*}$ & $3.16 / 4.75^{*}$ \\
\hline
\end{tabular}

Note. The superscript * indicates the values in the sun [28].

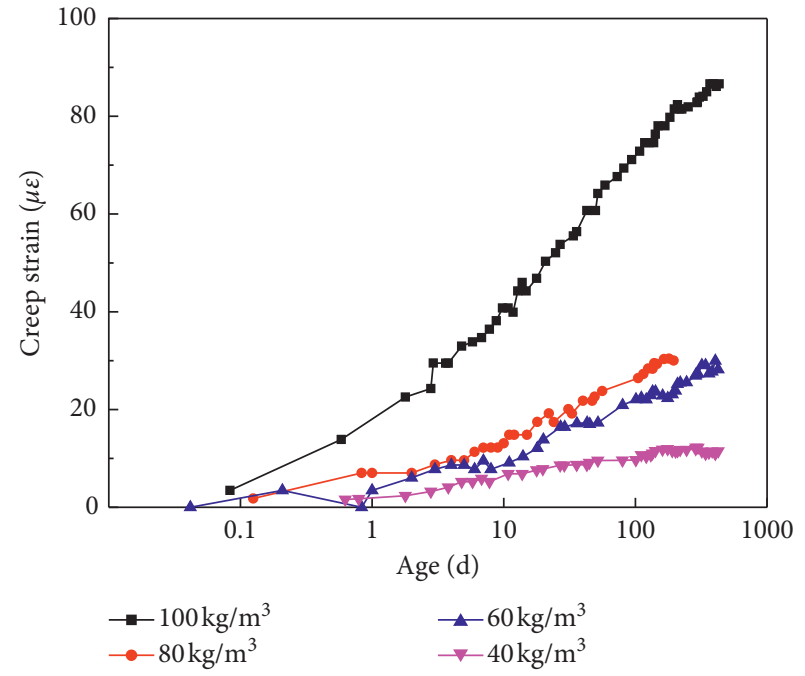

FIgURE 11: Creep curves of different cementing agent contents.

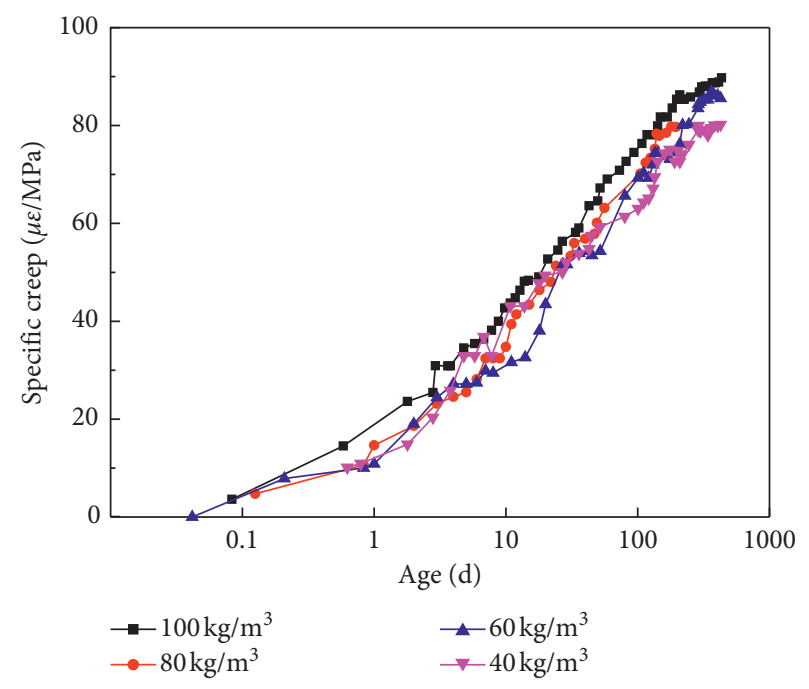

FIGURE 12: Specific creep curves of different cementing agent contents.

remains basically unchanged. The creep development law of CSG with different cementing agent content is similar, but as the cementing agent content decreases, its creep rate enters the slowing stage earlier and then enters the stable creep stage earlier. With the increase of cementing agent content, the creep deformation of CSG increased. The main reason is that the compressive strength of the specimen increases with the increase of cementing agent content, so the load applied in the test also increases correspondingly. From the point of view of the creep specimen itself, the main reason could be attributed to the relative increase of cementing agent between particles with the increase of cementing agent content, which makes the interfacial fluidity between particles become larger, because when the cementing agent content is $100 \mathrm{~kg} / \mathrm{m}^{3}$, the load of the compressive specimens rises greatly, and the creep of the specimens was also larger. A total of 420 days were counted in this test. Due to the large dispersion of CSG, there may be some problems in the casting process of samples with a cementing agent content of $80 \mathrm{~kg} / \mathrm{m}^{3}$. After the loading time reaches 195 days, the sample is damaged and the sensor value is abnormal.

It can be seen from Figure 12 that the specific creep curve of CSG with different cementing agent content shows the same trend of rapid growth in the early stage and slowdown in the late stage as the creep curve, and the change rate is basically the same. Furthermore, it shows that when the cementing agent content increased from $40 \mathrm{~kg} / \mathrm{m}^{3}$ to $100 \mathrm{~kg} / \mathrm{m}^{3}$, the specific creep value only increased by $9.52 \times 10^{-6} / \mathrm{MPa}$. That is, the average increment of creep limit is only $3.17 \times 10^{-6} / \mathrm{MPa}$ for every $20 \mathrm{~kg} / \mathrm{m}^{3}$ increase of cementing agent content, and it can be considered that the creep curve is basically the same. It indicates that the creep effect produced by the unit stress of CSG was basically the same under low stress. The reason is that the interfacial characteristics between the particles are determined by the cementing agent when the CSG was simplified as granular material. The different cementing agent contents mainly affected the thickness of the intergranular bonding layer, while the composition of the cementitious agent (cement : fly ash : water $=1: 1: 2$ ) was not affected. The creep development law of CSG is mainly determined by the interface characteristics. Therefore, even though the amount of cementing agent content was low, its creep mechanism was similar to that of concrete. The creep of concrete is generally not affected by the cementing agent content; however, the specific creep value of CSG still has a certain amount of fluctuation. It is mainly due to the low cementing agent content of CSG and the large discrete type of material particles, so there is relative displacement between particles under load.

The comparison diagram of the specific creep curves of CSG and Longtan RCC [30] material is shown in Figure 13. It can be seen from the diagram that the final creep value of CSG was greater than RCC. The main reason was due to the less slurry in CSG, which resulted in the relatively soft CSG. When external loads were applied on the CSG, its slurry structure would undergo a fast deformation. 


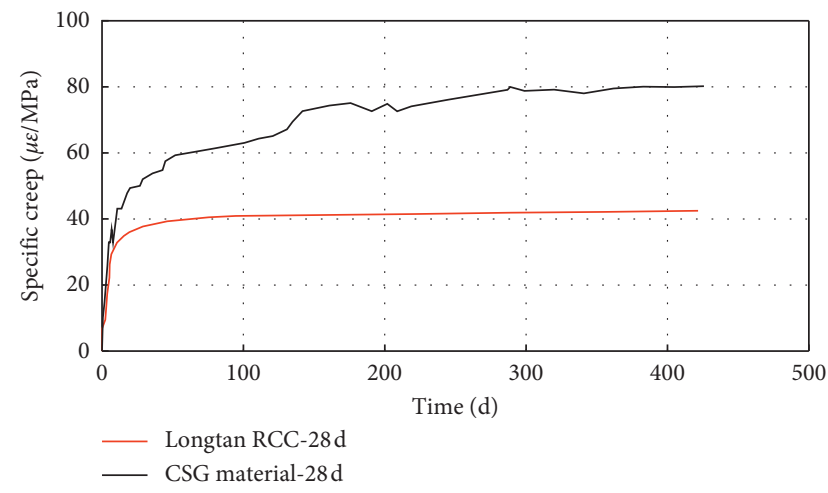

Figure 13: Comparison of specific creep of different materials.

3.2. Specific Creep Model. The temperature stress relaxation caused by creep deformation of concrete will restrain the generation and development of cracks, so it is necessary to take the creep of concrete into account when calculating the temperature stress. In the calculation of specific temperature stress, the creep formula compliance is substituted into the program for calculation. Temperature has a certain influence on the creep of concrete [31,32] but generally does not need to be considered in the calculation of temperature stress of concrete dam [30]. Generally, creep test is conducted at a constant temperature of $20^{\circ} \mathrm{C}$, and the maximum temperature in the dam is about $30-40^{\circ} \mathrm{C}$. Especially in the CSG dam with low cementing agent content, the dam body temperature is lower. Therefore, the error caused by the influence of temperature on creep can be ignored in the simulation of dam temperature control. The specific creep $C(t, \tau)$ was related not only to the holding time $(t-\tau)$ but also to the age of concrete under loading $\tau$. The smaller the age of concrete under load, the greater the specific creep of concrete. As introduced in [30], the aging theory assumes that the creep curve of concrete has the property of being parallel along the $\varepsilon$ axis, as shown in Figure 14. The above formula shows that if you $\operatorname{shift} C\left(t, \tau_{0}\right)$ down the $\varepsilon$ axis by $C\left(\tau, \tau_{0}\right)$, you get $C(t, \tau)$. That is to say, the aging theory holds that the creep curve changes in different loading ages are similar and that the creep cannot be recovered after unloading. Therefore, in the aging theory, only one creep curve model formula needs to be solved, and the rest of the ages can be calculated. Therefore, this paper focuses on 28-day creep model. The advantage of this theory is that the number of test groups can be reduced. However, the model obtained by experiment has some minor imperfections.

There was many expressions of specific creep, such as exponential function, composite power exponential function, and logarithmic function. In the finite element calculation, it was unnecessary to record stress history by using the characteristics of exponential function. This not only saved a big storage capacity but also reduced the computational workload. Therefore, the creep expression expressed by exponential function generated a wide range of stresses. In this paper, the theoretical formula of concrete elastic creep based on superposition principle proposed by Zhu [30] was used as follows:

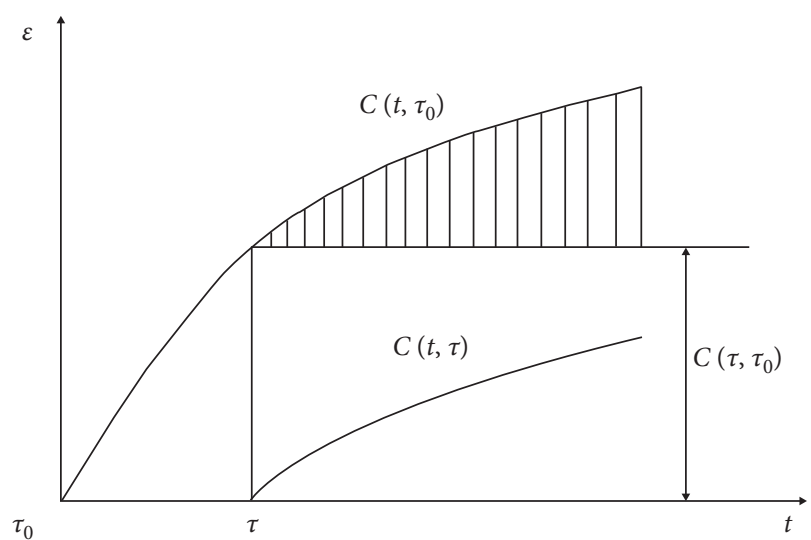

Figure 14: Schematic diagram of aging theory.

$$
C(t, \tau)=\sum_{i=1}^{n}\left(f_{i}+g_{i} \tau^{-p_{i}}\right)\left[1-e^{-r_{i}(t-\tau)}\right],
$$

where $f_{i}, g_{i}, p_{i}$, and $r_{i}$ refer to constants.

Generally, if $n$ takes 2, then formula (3) can be obtained. Figure 15 shows that the fitting result was good and the correlation coefficient reached 0.997 , which showed that the creep formula of concrete was also suitable for CSG. The fitting formula was shown as (4).

$$
\begin{aligned}
C(t, \tau)= & \left(f_{1}+g_{1} \tau^{-p_{1}}\right)\left[1-e^{-r_{1}(t-\tau)}\right] \\
& +\left(f_{2}+g_{2} \tau^{-p_{2}}\right)\left[1-e^{-r_{2}(t-\tau)}\right], \\
C(t, \tau)= & \left(35.4+49.5 \tau^{-0.8}\right)\left[1-e^{-0.09(t-\tau)}\right] \\
& +\left(20.1+60.5 \tau^{-0.15}\right)\left[1-e^{-0.008(t-\tau)}\right] .
\end{aligned}
$$

3.3. Creep Temperature Stress of CSG. In this section, Shanxi Shoukoubao reservoir CSG dam [33] was chosen as computational model. According to whether considering creep, the temperature stress of CSG dam was analyzed, respectively. The stress variation rule of CSG dam with different cementing agent content and different thickness insulation layer was analyzed to discuss whether the temperature control measures should be taken.

3.3.1. Engineering Situation. The total reservoir capacity is 9.8 million $\mathrm{m}^{3}$, which belongs to the category of a small (1) reservoir. Its crest elevation is $1243.6 \mathrm{~m}$, crest length is $354 \mathrm{~m}$, maximum height is $61.6 \mathrm{~m}$, crest width is $6 \mathrm{~m}$, and upstream and downstream slopes are $1: 0.6$.

3.3.2. Temperature Data. The multiyear monthly mean temperature curve of the dam site adopts the cosine function expression proposed by Zhu [34]:

$$
T(\tau)=T_{\mathrm{am}}+A_{\mathrm{a}} * \cos \left[\frac{\pi}{6}(\tau-6.5)\right],
$$

where $T(\tau)$ is the monthly average temperature, $\tau$ is the time (unit: month), $T_{\mathrm{am}}$ is the annual average temperature, and $A_{\mathrm{a}}$ is the annual variation of temperature. 


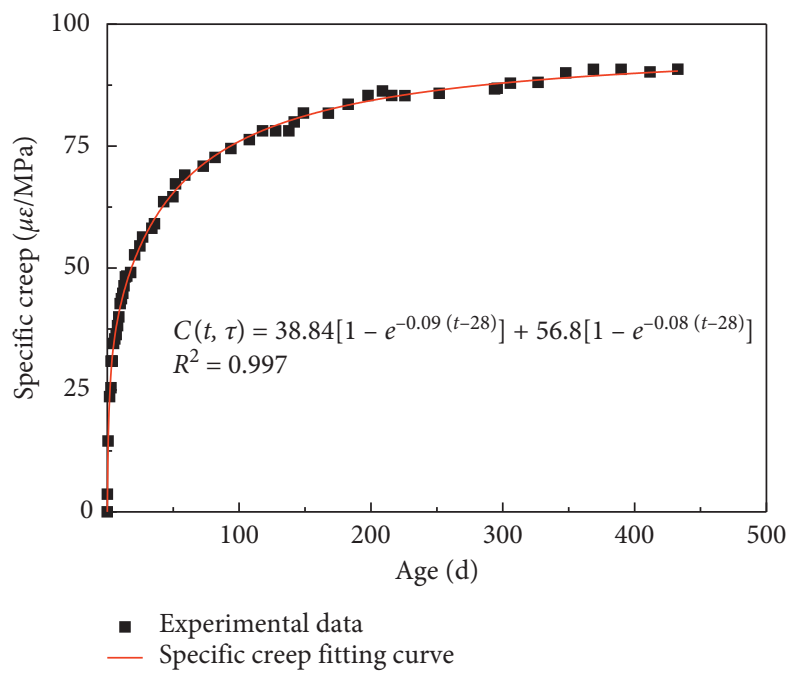

Figure 15: Specific creep fitting curve of CSG with loading age of 28 days.

TABLE 3: The local monthly mean temperature.

\begin{tabular}{|c|c|c|c|c|c|c|c|c|c|c|c|c|}
\hline Month & 1 & 2 & 3 & 4 & 5 & 6 & 7 & 8 & 9 & 10 & 11 & 12 \\
\hline Temperature $\left({ }^{\circ} \mathrm{C}\right)$ & -10 & -6.6 & 0.5 & 9.2 & 16.1 & 20.2 & 21.6 & 19.6 & 14.5 & 7.8 & -1.1 & -7.6 \\
\hline
\end{tabular}

TABle 4: The thermodynamic and mechanical parameters of CSG dam.

\begin{tabular}{lccr}
\hline Cementing agent content $\left(\mathrm{kg} / \mathrm{m}^{3}\right)$ & Adiabatic temperature rise $\left({ }^{\circ} \mathrm{C}\right)$ & Elastic modulus $(\mathrm{GPa})$ & Tensile strength $(\mathrm{MPa})$ \\
\hline 100 & $\theta(\tau)=16.84 \tau /(2.72+\tau)$ & $E(\tau)=13.89 \tau /(5.46+\tau)$ & $\sigma(\tau)=0.84 \tau /(3.51+\tau)$ \\
120 & $\theta(\tau)=21.58 \tau /(2.79+\tau)$ & $E(\tau)=15.14 \tau /(5.12+\tau)$ & $\sigma(\tau)=0.94 \tau /(3.09+\tau)$ \\
140 & $\theta(\tau)=26.96 \tau /(2.80+\tau)$ & $E(\tau)=16.84 \tau /(4.72+\tau)$ & $\sigma(\tau)=1.14 \tau /(3.33+\tau)$ \\
\hline
\end{tabular}

According to the statistics of local meteorological elements, the annual average temperature in the region is $7.01^{\circ} \mathrm{C}$, with the highest temperature in July. The multiyear monthly average temperature is listed in Table 3.

Based on the data obtained in Table 4, the multiyear monthly average temperature curve of the dam site is expressed as follows:

$$
T(\tau)=7.01+15.57 * \cos \left[\frac{\pi}{6}(\tau-6.5)\right]
$$

3.3.3. Material Parameters. In the calculation, three relatively high cementing agent contents of 100, 120, and $140 \mathrm{~kg} /$ $\mathrm{m}^{3}$ were mainly considered. The thermal conductivity, specific heat capacity, and thermal expansion coefficient are $7.375\left(\mathrm{~kJ} /\left(\mathrm{m} \cdot \mathrm{h} \cdot{ }^{\circ} \mathrm{C}\right)\right), 0.99\left(\mathrm{~kJ} /\left(\mathrm{kg} .{ }^{\circ} \mathrm{C}\right)\right)$, and $0.56 \times 10^{-5}\left(1 /{ }^{\circ} \mathrm{C}\right)$, respectively. The values of other parameters according to different cementing agent content are shown in Table 4 .

3.3.4. Calculation Model. The dam section with 20 meters between two transverse joints was selected for analysis. The finite element mesh is shown in Figure 16. In this paper, the key point on the surface of overwintering layer (K1), the central key point of half elevation of dam body (K2), and the surface of the strongly constrained region key point (K3) were selected as the research objects. The key point diagram is shown in Figure 17.

3.3.5. Analysis of Temperature Stress. Figures 18 and 19 show the temperature stress time-dependent curves of K1 and $\mathrm{K} 2$. It can be seen that the stress at the surface point of the dam body changes periodically with time. The stress at the center point of the dam body presents a large tensile stress at the initial stage of casting due to the large surface temperature difference. Then, with the pouring of the upper layer concrete, the stress of the dam center point is gradually transformed into the compressive stress. Finally, due to the temperature drop of the dam body, the stress at the central point is transformed into tensile stress again. Creep has little influence on the change trend of temperature stress at key points of CSG dam, but the peak tensile stress can decrease by about $37 \%$ when creep was taken into account. Creep of CSG can effectively reduce stress peak, so it can simplify temperature control measures and bring about good economic benefits. Therefore, the influence of creep should be taken into account in the calculation of temperature control and crack prevention of CSG dam so as to accurately reflect the magnitude of stress and provide a basis for the research of temperature control and crack prevention.

Figures 20-22 show the creep temperature stress history curves of $\mathrm{K} 3$ with different thickness of insulation 


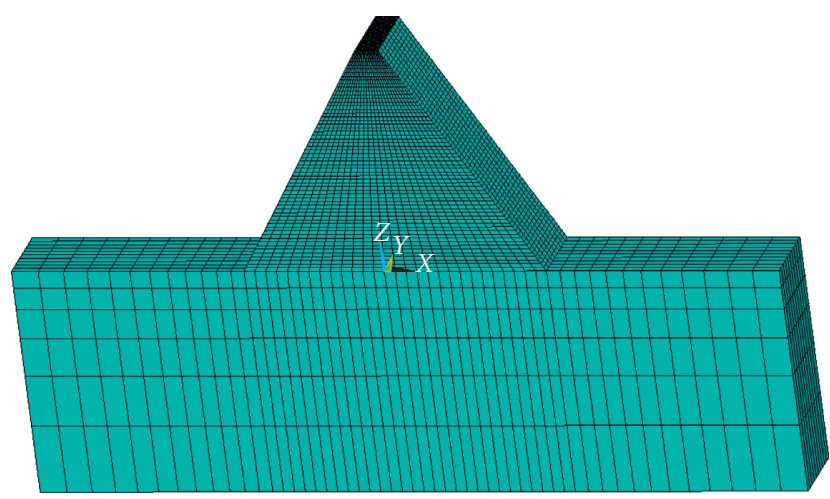

Figure 16: The finite element model.

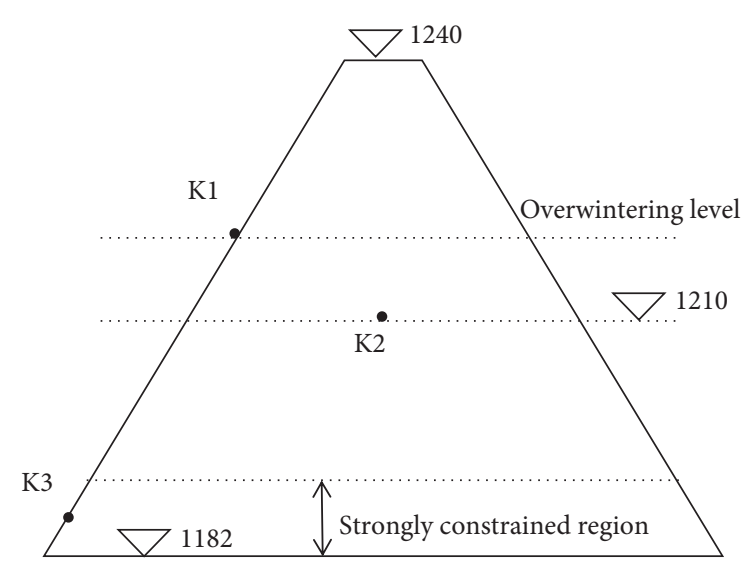

FIgURe 17: Key point diagram.

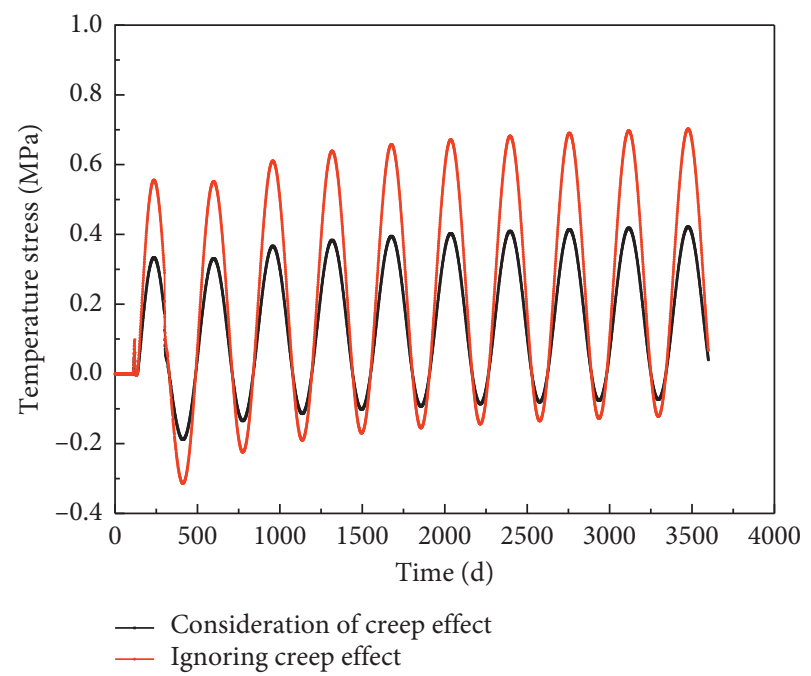

FIgURE 18: K1 temperature stress history curve.

layers when the cementing agent content was 100, 120, and $140 \mathrm{~kg} / \mathrm{m}^{3}$ (cement and fly ash ratio $1: 1$ ). It can be seen that the tensile stress on the surface of the dam increases gradually with the decrease of the thickness of the insulation layer of the dam body. When the cementing agent content was $100 \mathrm{~kg} / \mathrm{m}^{3}$, the temperature

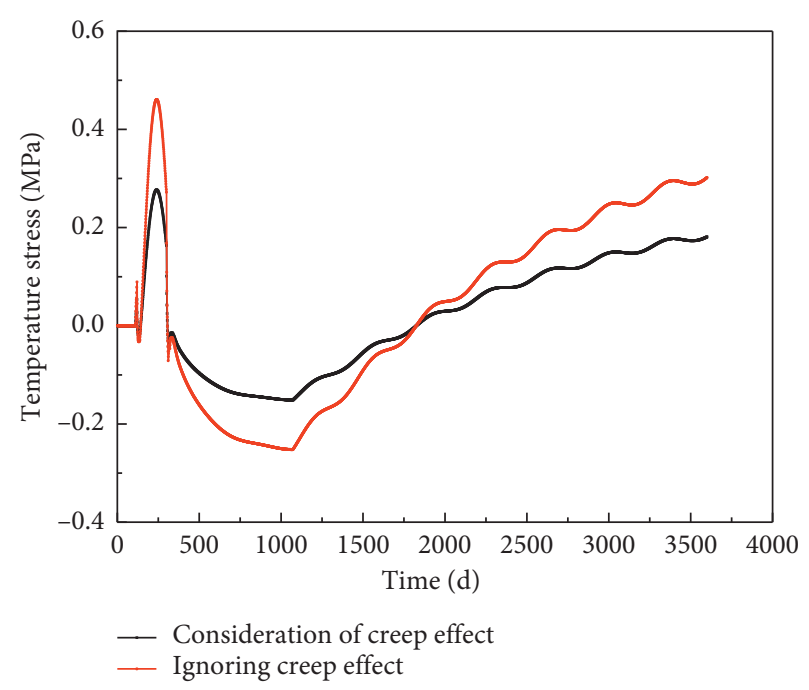

FIgURE 19: K2 temperature stress history curve.

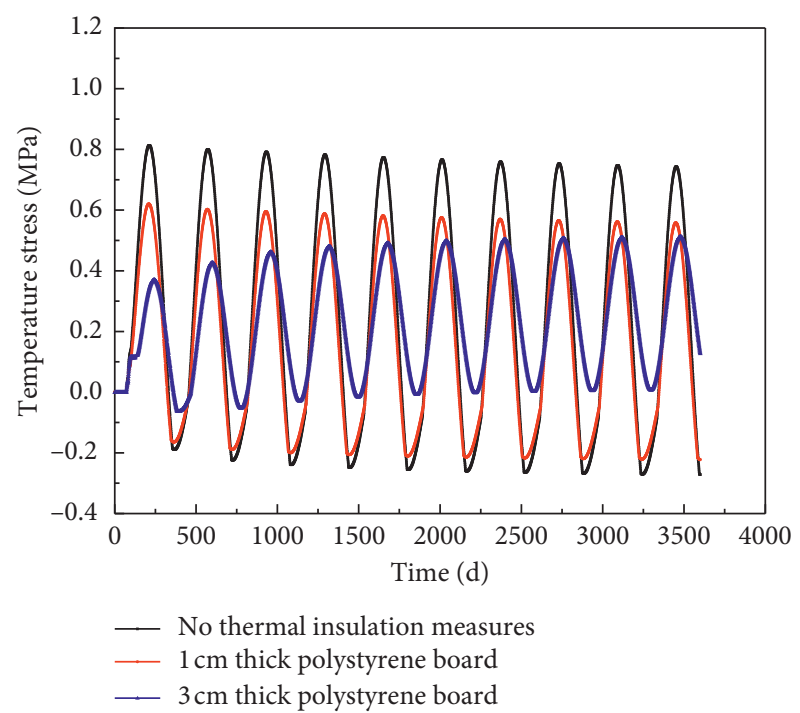

FIgURE 20: Temperature stress history curve of K3 at cementing agent content of $100 \mathrm{~kg} / \mathrm{m}^{3}$.

stress reached $0.82 \mathrm{MPa}$ at $\mathrm{K} 3$ point in the first winter, which closed the allowable tensile strength. The stress drop to $0.62 \mathrm{MPa}$ belongs to the allowable range when the polystyrene insulation board with thickness of $1 \mathrm{~cm}$ was adopted. When the cementing agent content reached $120 \mathrm{~kg} / \mathrm{m}^{3}$, there was a risk of cracking in the strongly restrained area without considering surface insulation measures. When the insulation thickness was increased to $1 \mathrm{~cm}$, the tensile stress was reduced to the allowable tensile strength. When the cementitious content reaches $140 \mathrm{~kg} / \mathrm{m}^{3}$, the maximum tensile stress reached $1.48 \mathrm{MPa}$, which obviously exceeded the allowable range. When $2 \mathrm{~cm}$ thick insulation measures are considered, the temperature stress dropped to $1.02 \mathrm{MPa}$ within the allowable range.

In this paper, temperature control and crack prevention of 60 meters high CSG dam in Northwest China are 


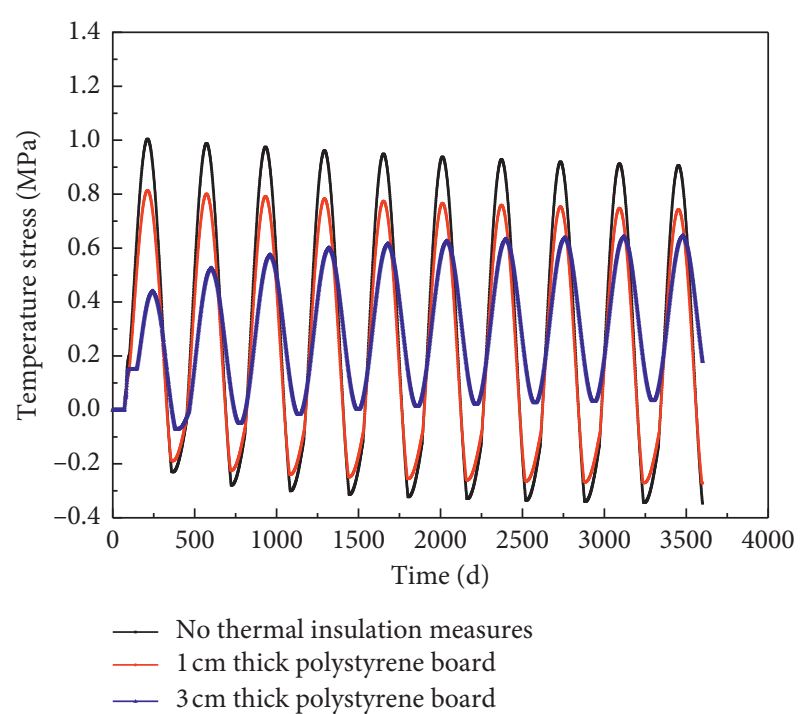

Figure 21: Temperature stress history curve of K3 at cementing agent content of $120 \mathrm{~kg} / \mathrm{m}^{3}$.

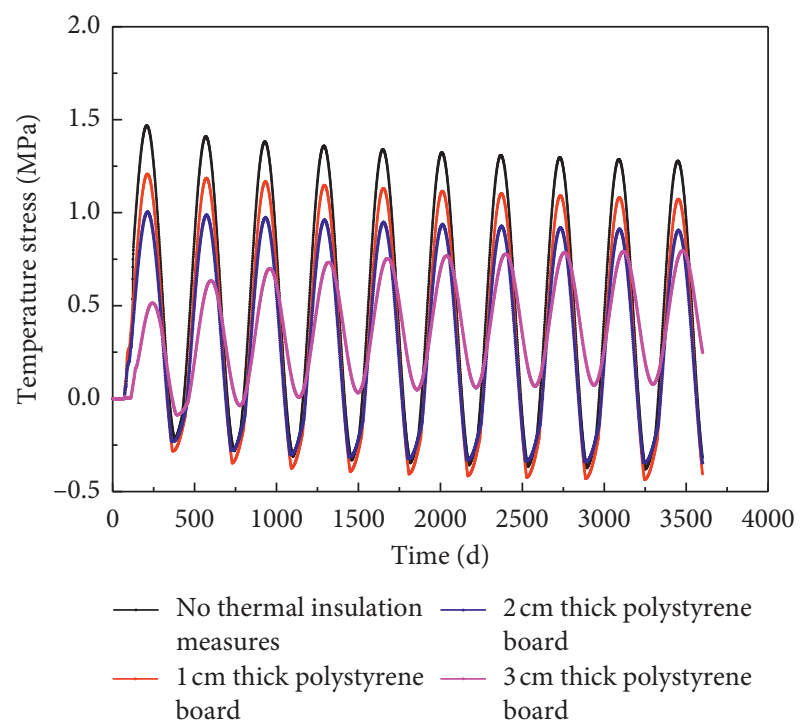

FIgURE 22: Temperature stress history curve of K3 at cementing agent content of $140 \mathrm{~kg} / \mathrm{m}^{3}$.

studied, but many conditions are still not considered, for example, the climate of different areas, the thickness of dam construction layer, dam height, and dam joints. All these factors have an impact on the selection of dam temperature control and crack prevention measures. Therefore, it cannot be generalized that the CSG dam did not need to consider temperature control measures, and it was determined according to the actual situation. At present, simple temperature control measures should be taken into account when building dams in cold areas with high cementing agent content. With the acquisition of specific creep model suitable for CSG dam, it can provide theoretical support for scholars and engineers to study the temperature stress and temperature control crack prevention of the dam.

\section{Conclusion}

This paper presented the results of creep tests conducted on CSG. Based on the test results and numerical simulation analysis, the following conclusions were obtained:

(1) The creep of CSG increased with the increase of cementing agent content. When the cementing agent content reached $100 \mathrm{~kg} / \mathrm{m}^{3}$, the increase was obvious. Without changing the contact interface characteristics between particles, the specific creep did not change significantly with the amount of cementing agent content. The specific creep of CSG was greater than that of RCC and had more effect on temperature stress release.

(2) An exponential specific creep model suitable for CSG was obtained, which can fully reflect the trend of subsequent specific creep of CSG. It provided a reference for the subsequent simulation of thermal stress of CSG dam.

(3) Considering the influence of creep, the temperature stress of the CSG dam decreased obviously, with a decrease range of about $37 \%$. In cold areas, when the cementing agent content reached $100 \mathrm{~kg} / \mathrm{m}^{3}$, it was suggested to consider the thermal insulation measures on the surface of the dam. With the increase of the cementing agent content, the surface insulation measures should be gradually thickened. In conclusion, whether the temperature control measures should be considered for CSG dam should be judged comprehensively according to the external conditions. It is not simply considered that the low cementing agent content of CSG dam did not need to consider the temperature control measures.

\section{Data Availability}

The data used to support the findings of this study are included in the article.

\section{Conflicts of Interest}

The authors declare that there are no conflicts of interest regarding the publication of this paper.

\section{Acknowledgments}

The authors would like to acknowledge the support by the National Key Research and Development Program during the 13th Five-Year Plan Period (2018YFC0406800), the National Natural Science Foundation projects (51979094), and the National Science and Technology Pillar Program during the 12th Five-Year Plan Period (2012BAD10B02).

\section{References}

[1] X. Cai, Y. Wu, X. Guo, and Y. Ming, "Research review of the cement sand and gravel (CSG) dam," Frontiers of Structural and Civil Engineering, vol. 6, no. 1, pp. 19-24, 2012. 
[2] J. Chen, X. Cai, E. Lale, J. Yang, and G. Cusatis, "Centrifuge modeling testing and multiscale analysis of cemented sand and gravel (CSG) dams," Construction and Building Materials, vol. 223, pp. 605-615, 2019.

[3] J. S. Jia, N. Liu, C. Y. Zheng, F. L. Ma, Z. K. Du, and Y. Wang, "Research progress and engineering application of cemented granular dam," Journal of Water Conservancy, vol. 47, no. 3, pp. 315-323, 2016.

[4] P. Londe and M. Lino, "The faced symmetrical hardfill dam: a new concept for RCC," International Water Power \& Dam Constructio, vol. 44, no. 2, pp. 19-24, 1992.

[5] J. Yang, Research on elastoplastic constitutive model of csg material and structural operating behavior of csg dam, Ph.D. thesis, Hohai university, Nanjing, China, 2018.

[6] J. S. Jia, F. L. Ma, and X. Y. Li, "Study on material characteristics and engineering application of CSG dam," Journal of Water Resources, vol. 37, no. 2, pp. 578-582, 2006.

[7] T. N. Lohani, L. Kongsukprasert, K. Watanabe, and F. Tatsuoka, "Strength and deformation properties of compacted cement-mixed gravel evaluated by triaxial compression tests," Soils and Foundations, vol. 44, no. 5, pp. 95-108, 2004.

[8] L. Kongsukprasert and F. Tatsuoka, "Ageing and viscous effects on the deformation and strength characteristics of cement-mixed gravelly soil in triaxial compression," Soils and Foundations, vol. 45, no. 6, pp. 55-74, 2005.

[9] X. Cai, Y. L. Wu, H. X. Li, and J. G. Yi, "Study on constitutive characteristics of cemented rockfill," Journal of Geotechnical Engineering, vol. 32, no. 9, pp. 1340-1344, 2010.

[10] J. Yang, X. Cai, Q. Pang et al., "Experimental study on the shear strength of cement-sand-gravel material," Advances in Materials Science and Engineering, vol. 2018, Article ID 2531642, 11 pages, 2018.

[11] W. Y. Liu, Research on temperature field and temperature creep stress of concrete structure, Ph.D. thesis, Tongji University, Shanghai, China,, 2004.

[12] Z. P. Bazant and W. P. Murphy, "Creep and shrinkage prediction model for analysis and design of concrete structuresmodel B3," Matériaux et Structures, vol. 28, no. 6, pp. 357-365, 1995.

[13] Z. P. Bazant and M. F. Kaplan, Concrete at High Temperatures: Material Properties and Mathematical Models, Longman, Harlow, UK, 1996.

[14] S. Staquet, B. Delsaute, A. Darquennes et al., "Design of a revisited TSTM system for testing concrete since setting time under free and restraint conditions," in Proceedings of the Concrack3-RILEM-JCI International Workshop on Crack Control of Mass Concrete and Related Issues Concerning EarlyAge of Concrete Structures, pp. 15-16, Paris, France, 2012.

[15] B. Delsaute, C. Boulay, and S. Staquet, "Creep testing of concrete since setting time by means of permanent and repeated minute-long loadings," Cement and Concrete Composites, vol. 73, pp. 75-88, 2016.

[16] B. Delsaute, J.-M. Torrenti, and S. Staquet, "Modeling basic creep of concrete since setting time," Cement and Concrete Composites, vol. 83, pp. 239-250, 2017.

[17] Y. Wu and R. Luna, "Numerical implementation of temperature and creep in mass concrete," Finite Elements in Analysis and Design, vol. 73, no. 2, pp. 97-108, 2016.

[18] A. A. Abdulrazeg, J. Noorzaei, P. Khanehzaei, M. S. Jaafar, and T. A. Mohammed, "Effect of temperature and creep on roller compacted concrete dam during the construction stages," Computer Modeling in Engineering and Sciences, vol. 68, no. 3, pp. 238-239, 2010.
[19] S. He, Z. Zhu, M. Lv, and H. Wang, "Experimental study on the creep behaviour of rock-filled concrete and self-compacting concrete," Construction and Building Materials, vol. 186, pp. 53-61, 2018.

[20] B. Delsaute and S. Staquet, "Development of strain-induced stresses in early age concrete composed of recycled gravel or sand," Journal of Advanced Concrete Technology, vol. 17, no. 6, pp. 319-334, 2019.

[21] X. W. Guo, Q. Zhao, S. T. Gu, and X. Cai, "Creep properties of granular materials based on viscoelastic contact," Geotechnical Mechanics, vol. 37, no. 2, pp. 105-112, 2016.

[22] X. W. Guo, J. L. Du, Q. Zhao, and X. Cai, "Creep test and longterm deformation prediction of cemented sand and gravel material," The People of the Yellow River, vol. 41, no. 9, pp. 149-154, 2019.

[23] W. Feng, Studies on cemented sand and gravel dam material and its application, Ph.D. thesis, China Academy of Water Resources, Beijing, China, 2013.

[24] H. Wu, Y. Peng, and Y. Yuan, "Study on simplified construction temperature control measures of CSG dam," Water Resources and Hydropower Technology, vol. 45, no. 1, pp. 76-84, 2015.

[25] SL678-2014, Technical Guideline for Cemented Granular Material Dams Particles, Ministry of Water Resources of the People's Republic of China, Beijing, China, 2014.

[26] Q. Zhao, "Study on creep behaviors of cemented sand and gravel based on micro-mechanics," Master thesis, Hohai Uuiversity, Nanjing, China, 2017.

[27] SL 352-2006, Test Code for Hydraulic Concrete, Ministry of Water Resources of the People's Republic of China, Beijing, China, 2006.

[28] M. Q. Sun, Study on Mechanical Properties, Durability and Dam Shape of Cemented Sand and Gravel, China Water Resources and Hydropower Press, Beijing, China, 2016.

[29] B. Delsaute, C. Boulay, J. Granja et al., "Testing concrete E-modulus at very early ages through several techniques: an inter-laboratory comparison," Strain, vol. 52, no. 2, pp. 91-109, 2016.

[30] B. F. Zhu, Temperature Stress and Temperature Control of Mass Concrete, China Water Conservancy and Hydropower Press, Beijing, China, 2nd edition, 2012.

[31] Z. P. Bažant, G. Cusatis, and L. Cedolin, “Temperature effect on concrete creep modeled by microprestress-solidification theory," Journal of Engineering Mechanics, vol. 130, no. 6, pp. 691-699, 2004.

[32] A. Sellier, S. Multon, L. Buffo-Lacarrière, T. Vidal, X. Bourbon, and G. Camps, "Concrete creep modelling for structural applications: non-linearity, multi-axiality, hydration, temperature and drying effects," Cement and Concrete Research, vol. 79, pp. 301-315, 2016.

[33] J. Jia, M. Lino, F. Jin, and C. Zheng, "The cemented material dam: a new, environmentally friendly type of dam," Engineering, vol. 2, no. 4, pp. 490-497, 2016.

[34] B. Zhu, Thermal Stresses and Temperature Control of Mass Concrete, Butterworth-Heinemann, Oxford, UK, 2013. 